\title{
El Salvador: un equilibrio imperfecto entre los votos y las botas
}

1 $n$ El Salvador, como señala el coronel Mariano Castro Morán, "el ejército da un golpe de Estado y casi inmediatamente delega el poder a su (o sus) representante(s) o delegado(s). En un lapso de trece a quince años, este representante o sus sucesores militares se vuelven intolerables para el pueblo, entonces el ejército da otro golpe de Estado y continua la secuencia hasta la fecha." 1

Esta práctica política, vigente desde la crisis de la dominación oligárquica a fines de los años treinta, y consolidada con el

${ }^{1}$ Mariano Castro Morán, Función politica del ejército salvadoreño en el presente siglo, UCA, San Salvador, 1984, p. 26. ascenso del general Maximiliano Hernández Martínez, favorecida posteriormente con el derrocamiento de éste en 1944 y por la influencia de posguerra, con la acelerada modernización de las estructuras económicas del país, generó una especie de "fantasma democrático", donde a partir de una visión elitista del ejercicio del gobierno sostenida en un mantenimiento del poder basado en una estrecha alianza entre la oligarquía y las fuerzas armadas, ${ }^{2}$ se buscaba frecuentemente el consenso a través de procesos electorales. Incluso la formación de los partidos políticos trató de ocultar la

${ }^{2}$ Rafael Guidos Béjar, El ascenso del militarismo en El Salvador, UCA, San Salvador, 1980. 
esencia antidemocrática del sistema de dominación política. Esto fue evidente con la permanentebúsqueda de un "partido oficial". En los años cincuenta fue a través del Partido Revolucionario de Unificación Democrática (PRUD), cuyo programa de gobierno incluso fue reformista, democrático y nacionalista, nacido a la par de la "revolución del 48",3 y luego, desde principios de los sesenta, con el Partido de Conciliación Nacional (PCN). De esta manera, en El Salvador se practican las elecciones con frecuencia, y su sistema electoral es uno de los más complejos de Centroamérica. Esto explica en parte porqué desde el derrocamiento de Hernández Martínez no se consagra en el poder un dictador, sino que se da una permanente rotación del mando ejecutivo del país.

El sistema electoral salvadoreño, desde fines de los años cuarenta y hasta la actualidad, sebasa en tres diferentes procesos de consulta: elecciones presidenciales, municipales y para la Asamblea. Las elecciones para presidente eran para periodos de seis años, y en la Constitución de 1961 se modificó a cinco años, con posibilidad de reelección. Hasta la actual constitución de 1983, las elecciones legislativas eran cada dos años y después de la constitución de 1983 se modifica ese periodo a tres. Hasta 1983 , la Asamblea se constituye de 54 diputados (no existe Senado), conformados de la siguiente manera: uno por departamento (catorce departamentos) y uno por más de 50000 habitantes $\multimap$ fracción de más de 15 000-. Desde 1983, la Asamblea se compone de 60 diputados. Las elecciones municipales, hasta 1983 , se celebraban cada dos años, en los 260

\footnotetext{
${ }^{3}$ Jorge Cáceres, Rafael Guidos Béjar y Rafael Menjivar, El Salvador: una bistoria sin lecciones, FLAcso, San José de Costa Rica, 1988.
}

municipios. Después de 1983 son electos los alcaldes cada tres años, con posibilidad de reelección. ${ }^{4}$

Entre 1950 y 1970 hubo en El Salvador cinco elecciones presidenciales, diez legislativas y diez municipales, todas ellas ganadas por el partido oficial (PRUD y PCN)..$^{5}$ Entre 1950 y 1960 la característica principal de los procesos electorales es el abstencionismo de la oposición. En ambos decenios es notable la sistemática ilegalización de los partidos políticos de izquierda. En las elecciones presidenciales de 1950, el candidato del partido oficial, Oscar Osorio, obtiene $57 \%$ de los votos y el de la oposición, postulado por el Partido de Acción Renovadora (PAR), 43\%. En las elecciones legislativas y municipales de 1952 y 1954 , el PRUD obtiene la mayoría absoluta, 54 diputaciones y 260 alcaldías (la oposición se abstuvo de participar). En las elecciones presidenciales de 1956 el PRUD obtiene 94\% de los votos para su candidato José María Lemus; en las legislativas gana las 54 posiciones de la Asamblea y en las municipales obtiene 258 alcaldías. En las elecciones de 1958, el partido oficial obtiene todas las diputaciones y 254 alcaldías, y en las elecciones de 1960 vuelve a obtener todos los asientos de la Asamblea y 250 alcaldías.

Entre 1960 y 1970 se dan importantes acontecimientos, entre los que destaca el golpe de Estado del 25 de enero de 1961 , pasando a gobernar el país un directorio cívico-militar. Se redacta una

${ }^{4}$ Ver Constitución politica de El Salvador, publicada en el Diario Oficial, El Salvador, t. 281, 16 de diciembre de 1983.

5 ICSPS, El Saluador. Election Factbook, 1967, pp. 27 y ss., tomada la información de 1950 a 1970 deMarioMonteforte Toledo, Centroamérica. Subdesarrolloy dependencia, vol. 2, IIS-UNaM, México, 1972, pp. 78-84. 


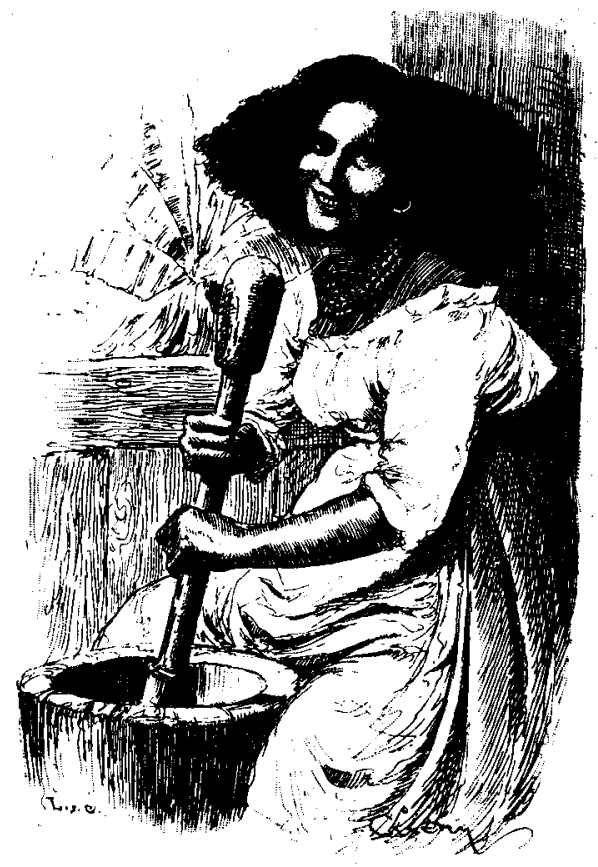

nueva constitución. Esta década destaca por la consolidación de la oposición política, organizada principalmente en tres partidos: el Partido Demócrata Cristiano (PDC), el Movimiento Nacional Revolucionario (MNR) de orientación socialdemócrata, y la Unión Democrática Nacionalista (UDN) de orientación comunista. En las elecciones presidenciales de 1962, el nuevo partido oficial, el PCN, obtiene $92 \%$ de los votos. La oposición votó en blanco. Ya en las elecciones legislativas y municipales de 1964, la oposición obtiene numerosasposiciones políticas: 32 diputados para el PCN; catorce para el PDC; y seis para el PAR. Igualmente, el PCN gana 223alcaldes y el PDC 37. En la década de 1960 es notable el incremento creciente delaminoriaparlamentaria de la oposición.

Entre los acontecimientos políticoelectorales más relevantes, destaca la victoria del PDC en las elecciones munici- pales de 1964, ganando la alcaldía de San Salvador para su candidato, José Napoleón Duarte (la capital concentraba la cuarta parte de la población). En 1966, en las elecciones legislativas y municipales, el PCN gana 31 diputaciones, el PDC quince, y el PAR cuatro. En las municipales, el PCN obtiene 167 alcaldias; el PDC 83 y otros partidos diez. En las presidenciales de 1967 el PCN gana la presidencia con $54 \%$ de la votación; el PDC 22\%; el PAR 14\% y el Partido Popular Salvadoreño (PPS) 10\%. En las legislativas y municipales de 1968, continúa bajando la cuota del PCN a 27 diputados; 19 para el PDC; cuatro para el pps y dos para el MNR.

Esta tendencia de participación creciente de la oposición política en los años sesenta es muy relevante. Incluso debido a ello se puede explicar el hecho de que ningún grupo armado opositor haya podido, como en la gran mayoría de 
los países latinoamericanos, extender la lucha guerrillera, siendo ésta inexistente en términos reales. La lucha electoral en El Salvador, aunque se restrinja al reparto de poder entre la oligarquía y las fuerzas armadas, va arraigándose en el país. A ello contribuye la configuración estructural de la nación, pues es un país densamente poblado, con una gran porción de la población ubicada en los centros urbanos y sin población indígena.

La lucha electoral en los setenta representa la frustración política del mecanismo electoral como forma de acceder al poder. Para las elecciones presidenciales de 1972 se conforma una coalición política denominada Unión Nacional Opositora (UNO), encabezada por el PDC, y donde participan el MNRy la UDN. Según la gran mayoría de los observadores políticos, la uno gana las elecciones pero se comete un gran fraude electoral, tras el cualse genera una creciente polarización política. La historia se repite en 1977. En las elecciones de 1972, las cifras oficiales reportan un resultado de 314000 votos para el PCN, versus, 292000 de la UNO. ${ }^{6}$ El desencanto por los métodos electorales se va generalizando en la década por múltiples factores, que van desde las repercusiones de la guerra con Honduras de 1969, tras la cual se generó un regreso muy importante de salvadoreños que laboraban en ese país, presionando enormemente por una reforma agraria, hasta el surgimiento de organizaciones denominadas "político-militares", las cuales se agruparán en el FMIN hacia $1980{ }^{7}$

\footnotetext{
${ }^{6}$ Sara Gordon, Crisis politica y guerra en El Salvador, Siglo XXI, Méxiço, 1989, p. 134.

${ }^{7}$ Esto lo hemos estudiado en detalle en Raúl Benítez Manaut, La teoría militar y la guerra civil en El Saluador, ucı, San Salvador, 1989, ver el capítulo "La guerra. Primer periodo, 1970-1980",
}

El 15 de octubre de 1979 el ejército salvadoreño se divide en dos. La fracción progresista, denominada "juventud militar", encabezada por el coronelAdolfo A. Majano, derroca al último gobernante del PCN, general Romero. Esta junta busca impulsar reformas estructurales. ${ }^{8}$ Los miembros progresistas de la junta van renunciando paulatinamente, y se consolida en ella el sector conservador de las fuerzas armadas y los dirigentes del PDC ligados a Napoleón Duarte. El 9 de enero de 1980, se firma un pacto entre el PDC y el alto mando de las fuerzas armadas, ${ }^{9}$ a fin de llevar adelante la contrainsurgencia según el esquema diseñado por la embajada de Estados Unidos desde donde con la llegada de los primeros asesores militares, se dirigirá la guerra de contrainsurgencia (se conforma el U.S. Military Group) ${ }^{10}$

Uno de los pilares de la reconstrucción del sistema político es el diseño de un nuevo juego de partidos políticos afín a los objetivos estratégicos de la con-

pp. 211-252. Los grupos armados que se consolidan en los setenta son: Fuerzas Populares de Liberación Farabundo Martí (FPL) 1970; Ejército Revolucionario del Pueblo (ERP) 1972; Resistencia Nacional (RN) 1975; Partido Revolucionario de los Trabajadores Centroamericanos (PRTC) 1976; y el Partido Comunista de El Salvador, quien a fines de 1979 acepta la lucha armada como método para alcanzar el poder político, creando para ello las Fuerzas Armadas de Liberación (FAL) El Frente Farabundo Martí se funda el 10 de octubre de 1980.

${ }^{8}$ Se impulsaron tres reformas: agraria, nacionalización del comercio exterior y nacionalización de la banca.

9 "Pacto Democracia Cristiana-Fuerza Armada el 9 de enero de 1980. La Fuerza Armada al pueblo salvadoreño", en Mariano Castro Morán, Función política del ejército saluadoreño en el presentesiglo, op. cit., pp. 416-419.

${ }^{10}$ Ver Raúl Benitez Manaut, "Guerra e intervención norteamericana", en Edgar Jiménez et al. El Salvador: guerra, politica y paz (1979-1988), CINAS-CRIES, San Salvador, 1988. 
trainsurgencia (la derrota del FMLN). Para ello, se estimula un juego democrático restringido, donde participan los partidos ubicados del centro del espectro polí-tico a la derecha, y se impide la participación de los partidos socialdemócratas y de izquierda, como el MNR y la UDN, así como unz escición progresista del PDC, surgida a principios de 1980, denomi-nada Movimiento Popular Social Cris-tiano (MPSC). La exclusión de estas fuerzas se $\mathrm{da}$, entre otras razones, porque habían decidido formar parte del Frente Democrático Revolucionario (FDR), fundado en abril de 1980 , mismo que se integrará a una alianza con el FMLN. ${ }^{11}$

Entre otros factores, el pilar político de la contrainsurgencia se basa en los procesos electorales ya que, en el conjunto de la región centroamericana, El Salvador ocupa un lugar privilegiado como un país donde, después de Costa Rica, se ha vivido con regularidad una vida política donde las elecciones se habían arraigado en la cultura de la población. Por ello se explica que a pesar de darse constantes golpes militares y gobiernos de facto nunca desde el derrocamiento de Hernández Martínez, fue posible abortar las elecciones como mecanismo de legitimidad y búsqueda de consenso, aunque en los cincuenta se dieran sin participación de la oposición y en los sesenta se restringiera la existencia legal de los partidos de izquierda, ${ }^{12}$

\footnotetext{
"Ver cINAS, El Saluador proceso político y guerra (1979-1986), Cuaderno de divulgación, núm. 4, San Salvador, noviembre de 1987.

${ }^{12}$ La exclusión de los partidos de izquierda y los procedimientos antidemocráticos del gobierno para eliminar del escrutinio los votos en su contra ocurren a lo largo del proceso electoral, impidiendo el proselitismo de los partidos entre ciertos sectores, principalmente el rural o negándoles el registro. En el campo incluso se emplea la utilización del terror paramilitar a través de institucio-
}

así como en los años setenta éstas se hayan distorsionado a través de los grandes fraudes, desembocando en el estallido de la guerra civil. Una investigación que intenta medir cuantitativamente el grado de "avance democrático" delos distintos países de Centroamérica a partir de cinco variables, concluye que El Salvador, después de Costa Rica, es el país "más democrático" de la región. Le siguen Guatemala, Honduras y Nicaragua. Las variables empleadas son: 1) libertad de expresión; 2) elecciones libres; 3) libre organización de los partidos políticos; 4) independencia del poder judicial, y 5) supremacia civil sobre la elite castrense. ${ }^{13}$

En El Salvador una de las constantes políticas que se observan en la forma y los mecanismos que el Estado emplea para lograr el control político es la conformación de partidos oficiales. En la época del general Maximiliano Hernández Martínez, inspirado en los partidos fascistas de la época, se organiza el partido Pro Patria; en los años cincuenta el PRUD; en los sesenta y setenta el PCN, y en los ochenta el PDC. ¿¿Se consolidará ARENA

nes como la Organización Democrática Nacionalista (ORDEN), para realizar acciones paramilitares que cada vez eran más necesarias para la dominación oligárquica. Ver Allan Na irm "De Kennedy a Reagan. El Salvador y la disciplina de la muerten, Nexos, año vil, vol. 7, núm. 79, julio de 1984. Incluso la exclusión de la izquierda se realiza legalmente, a través de las disposiciones del Consejo Central de Elecciones. Ver Consejo Central de Elecciones, Resoluciones del Consejo Central de Elecciones, 1965-1968, Imprenta Nacional, San Salvador, s.f. En este documento se señala: "Nuestra Constitución...desde que prohíbe la propaganda de doctrinas anárquicas y...contrarias a la democracia que ella reconoce, no permite la propagación de doctrinas y por consiguente la organización de partidos políticos que las propaguen... entre las cuales está el inciso $2^{\circ}$ del artículo 20 de la Ley Electoral."

${ }^{13}$ Mitchell A. Seligson "Development, democratization, and decay: Central America at the cross- 
como el partido oficial en los noventa? Una de las características principales es que estos partidos están financiados por la oligarquía y avalados por el alto mando. En el caso del PDC, si bien la forma en que accede al poder en 1980 no es a través de un proceso electoral sino mediante un pacto político; éste no cuenta nunca con el apoyo oligárquico, por lo que la oligarquía se reorganiza independientemente y funda, en 1981, el partido Alianza Republicana Nacionalista (ARENA). No obstante, el PDC cuenta con el respaldo incondicional de un nuevo factor de poder en el país que se transforma en decisivo a lo largo de la década de los ochenta por la guerra civil: la embajada de Estados Unidos. El PDC desde 1982 se legitima políticamente a través de las elecciones. ARENA, por su parte, es "oposición política" hasta que logra ocupar los principales espacios de poder en 1988 y 1989.

Por la polarización política que se da en el país en 1980 entre el sectór prooligárquico y proestadunidense y el sector democrático y.revolucionarioorganizado en la coalición FDR-FMLN, se presenta un divorcioentre el conflictopolítico real, yel régimen politico formal-institucional. La reconstrucción del sistéma político se da sobre la base de este último, donde participan las fuerzas políticas ubicadas del centro a la extrema derecha, y se excluye a los partidos que participan del FDR y, por supuesto, del FMLN. De esta manera, la principal contradicción en el país se traslada de la lucha política a la guerra y los ritmos de "lo político" se subordinan a la correlación defuerzas que

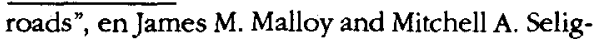
son (comps.), Authoritarians and Democrats. Regime Transition in Latin America, University of Pittsburgh Press, Pittsburgh, 1986. se da en el campo de batalla. Esta sobredeterminación de lo militar sobre lo político se observa principalmente entre 1981-87 y hasta la firma de los acuerdos de Esquipulas II.

De 1980 a 1982 gobierna de facto la junta cívico-militar, encabezada por $\mathrm{Na}$ poleón Duarte. ${ }^{14}$ En 1981 se emitieron una serie de decretos electorales y de partidos políticos que posibilitaron la participación de un número importante de fuerzas políticas en las elecciones constituyentes. ${ }^{15} \mathrm{El}$ régimen organiza un nuevo proceso electoral, a partir de la convocatoria a elecciones para la Asamblea Constituyente a efectuarse el día 28 de marzo de 1982.

En las elecciones de marzo de 1982 participaron seis partidos (ver cuadros 1

${ }^{14}$ Este periodo es analizado en detalle en Enrique Baloyra, El Salvador en transición, UCA, San Salvador, 1984. Baloyra sostiene la tesis de que El Salvador pasa por un momento de transición de un régimen militar semidictatorial a uno democrático, con el impulso a un nuevo régimen político. Esta tesis no toma en cuenta que el régimen político responde a un diseño contrainsurgente promovido por Estados Unidos y además es excluyente de un conjunto importante de fuerzas políticas ubicadas del centro político a la izquierda. Esta tesis la sostiene Baloyra a partir de observar la realidad política del país, particularmente las elecciones para la Asamblea Constituyente. Baloyra menciona: "La mayoría de los observadores de la elección salvadoreña...y la mayoría de los representantes de los medios de comunicación internacionales que llegaron para informar sobre el evento, coinciden en que la elección fue genuina. La elección ofreció una posibilidad de escoger, limitada, pero real; hubo intimidación latente y patente, pero no provenía de una sola fuente; el proceso fue ordenado y se contaron los votos sin manipulación", p. 230.

${ }^{15} \mathrm{Ver}$ "Anteproyecto de ley de partidos", presentadopor el Consejo Centralde Elecciones (mayo de 1981); decreto 743: "Ley transitoria sobre Constitución e inscripción de partidos políticos" (julio de 1981); y "Ley electoral transitoria, aprobada por la Junta de Gobiemo el 18 de diciembre de 1981" (decreto 914). 


\begin{tabular}{cccccc}
\multicolumn{5}{c}{ Cuadro 1 } \\
ELECCIONES DEL 28/III/ 1982 \\
Porcentajes de votos por partido \\
PDC & $P O P$ & $A D$ & $P C N$ & PPS & ARENA \\
$40.27 \%$ & $0.93 \%$ & $7.44 \%$ & $19.15 \%$ & $2.92 \%$ & $29.29 \%$ \\
& centro-derecha & & \multicolumn{3}{c}{ extrema-derecha }
\end{tabular}

Fuente: Ricardo Córdova, "Periodización del proceso de crisis", en El Saluador: guerra, política y paz (1979-1988), CINAS/CRIEs, San Salvador, 1988, p. 89.

\section{Cuadro 2}

$\begin{array}{cc}\text { COMPOSICION DE LA ASAMBLEA CONSTTTUYENTE } \\ \text { Partidos } & \text { Diputados } \\ \text { PDC } & 24 \\ \text { ARENA } & 19 \\ \text { PCN } & 14 \\ \text { AD } & 2 \\ \text { PPS } & 1 \\ \text { Total } & 60\end{array}$

Fuente: Ricardo Córdova, "Periodización del proceso de crisis", op. cit., p. 90.

y 2), de los cuales la votación se reparte en porcentajes importantes entre el PDC (40.27\%), ARENA (29.29\%) y el PCN (19.15\%). La Asamblea Constituyente, responsable de escribir la nueva constitución, se compone de la siguente manera: 24 diputados para el PDC, 19 para ARENA, catorce para el PCN, dos para Acción Democrática (AD) y uno para el Partido Popular Salvadoreño (PPS). ${ }^{16}$ Lo más notable de este proceso electoral es que, a pesar de las predicciones y los deseos del PDC y Estados Unidos, este partido se encuentra en una posición débil frente a un conglomerado fuerte de partidos de derecha y extrema derecha (principalmente el PCN y ARENA). De esa forma, mientras se redacta la nueva

${ }^{16}$ Ricardo Córdova "Periodización del proceso de crisis (1979-1988), en El Salvador: guerra, politica y paz (1979-1988), op. cit., p. 90. constitución y se da un proceso electoral constitucional para presidente, el mando ejecutivo del país se aglutina con base en un pacto político donde los ministerios se distribuyen según el porcentaje exacto de votos para la Asamblea. Igualmente la Asamblea, por el predominio de la derecha y extrema derecha, es presidida por el mayor Roberto D'Abuisson, máximo dirigente de ARENA. El 3 de agosto de 1982 se firma el Pacto de Apaneca, mediante el cual se constituye el Gobierno de Unidad Nacional. ${ }^{17}$ Este pacto fue

${ }^{17} \mathrm{El}$ poder se reparte tras el Pacto de Apaneca de la siguente manera: una comisión política formada por el presidente Álvaro Magaña, un miembro de las fuerzas armadas y tres vicepresidentes, uno del PDC, uno de ARENA y uno del PCN; también forman parte de la comisión política Fidel Chávez Mena del PDC; el presidente de la Asamblea Legislativa, Roberto D'Abuisson, un representante del 


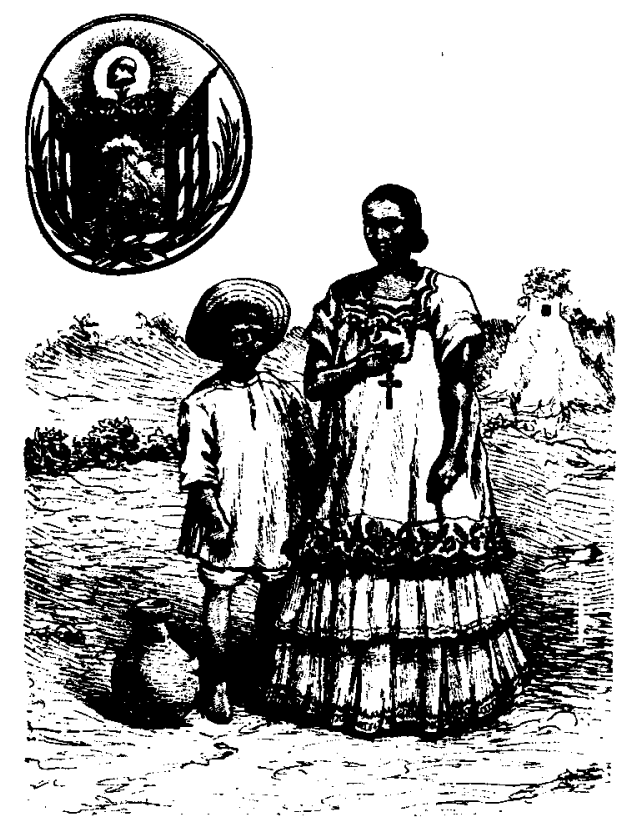

promovido por la embajada de Estados Unidos y el alto mando de las fuerzas armadas y en él se elige al banquero Álvaro Magaña como presidente provisional. El nuevo presidente enfrenta la crisis politica en un precario equilibrio entre las posiciones prooligárquicas y las reformistas (estamos hablando del reformismo contrainsurgente, según lo impulsa el PDC y lo concibe Estados Unidos como las reformas mínimas necesarias para enfrentar el avance del FMLN). Las funciones del nuevo gobierno son la redacción de la nueva constitución, bajo la responsabilidad de la Asamblea Constituyente (cuando ésta redacta la Constitución, en diciembre de 1983, se transforma en Asamblea Legislativa), y la organi-

PCN y otro del PPS. El texto del Pacto de Apaneca se puede consultar en Estudios Centroamericanos (ECA), vol. XXXVII, núms. 407-408, sep-oct. de 1982, San Salvador, Pp. 974-975. zación de las futuras elecciones presidenciales. ${ }^{18}$

Los dos años de gobierno de Magaña se caracterizan por la profundización de la guerra civil en el terreno militar y la competencia en el político, principalmente entre el PDC y ARENA. El sistema político se va configurando con base en una tendencia al bipartidismo entre el PDC Y ARENA, $v$ a la disminución creciente de la votación del resto de los partidos, principalmente del PCN. Esto se explica principalmente porque ARENA representa una nueva derecha, que sostiene un discurso acorde a la realidad del país. Su discurso político está militarizado y su eje ideológico se circunscribe a la idea de la guerra total contra el FMLN. Por su

${ }^{18}$ Ver Sara Gordon "Las vías de la reconstitución del régimen salvadoreño", en ciNas, El Salvador proceso político y guerra (1979-1986), op. cit. 

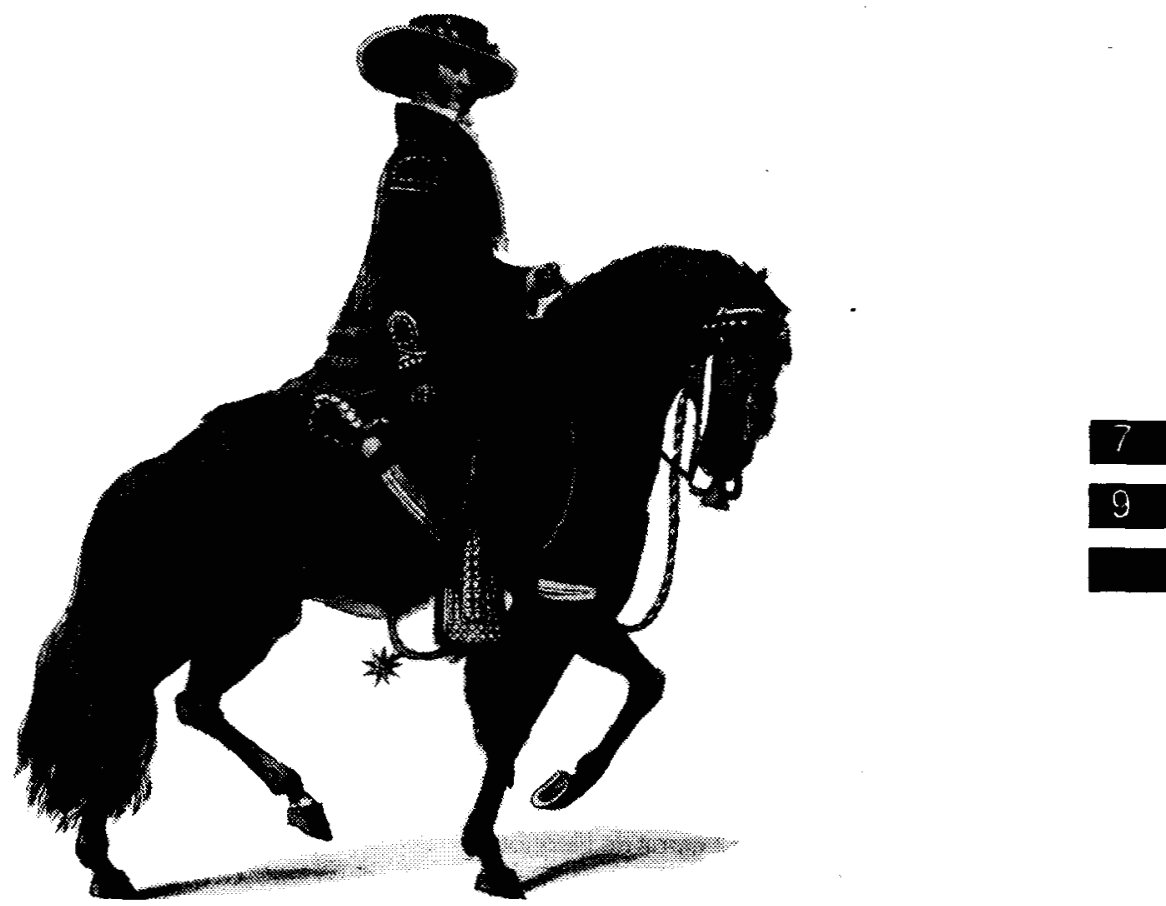

parte, el PDC basa su discurso en la idea de que representa una opción de centro, capaz de atraer a aquellos sectores de la población que son potenciales simpatizantes del FDR-FMLN. Para ello defiende la existencia de las reformas instauradas desde 1979, aunque en el fondo éstas estén bastante limitadas en su cobertura real.

En las elecciones presidenciales de marzo de 1984, esta competencia política es la que determina una cerrada votación donde ningún partido alcanza la mayoría absoluta que establece la constitución para alcanzar el puesto de presidente, por lo que se organiza una segunda ronda (ver cuadros 3 y 4). El PDC obtiene $43.41 \%$, ARENA $29.77 \%$ y el PCN $19.31 \%$. Una votación muy similar a la de 1982. La segunda ronda, realizada el 6 de mayo, donde compite Napoleón Duarte contra D'Abuisson, es ganada por el candidato del PDC, obteniendo 53.59\% de los votos, contra $46.41 \%$ para ARENA. ${ }^{19}$

$\mathrm{El}$ auge del reformismo contrainsurgente se da a partir del triunfo de Duarte y hasta 1986. Esto es posible por la promesa hecha por el PDC de: 1) democratizar al país; 2) lograr la recuperación económica, y 3) alcanzar la paz. En las elecciones legislativas y municipales de marzo de 1985 se observa el clímax del apoyo de la población al PDC. Los resultados por vez primera (y única) le otorgan una mayoría absoluta en la votación, ganando $52.35 \%$ de los votos de la Asamblea. ARENA logra $29.27 \%$ y el PCN $8.36 \%$ (ver cuadro 5). ${ }^{20}$ Hacia fines de

${ }^{19}$ Ignacio Ellacuría "Visión de conjunto de las elecciones de 1984", en Estudios Centroamericanos (ECA), vol. XXXIX, núm. 426-427, abril-mayo de 1984, San Salvador.

${ }^{20}$ Segundo Montes, "Ias elecciones del 20 de marzo de 1988", en Estudios Centroamericanos 


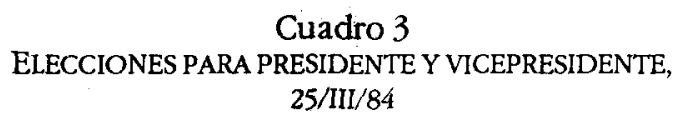

\begin{tabular}{|c|c|c|c|c|c|c|}
\hline & ARENA & $P D C$ & $P C N$ & MERECEN & PAISA & $P P S$ \\
\hline Total & 376917 & 549727 & 244556 & 6645 & 15430 & 24395 \\
\hline \multirow[t]{2}{*}{$\begin{array}{l}\text { Porcentaje } \\
\text { del total }\end{array}$} & 29.76 & 43.41 & 19.31 & 0.52 & 1.21 & 1.92 \\
\hline & $A D$ & $P O P$ & Vátidos & Nulos & & Abstenciones \\
\hline Total & 43929 & 4677 & 1266276 & 104557 & & 41736 \\
\hline $\begin{array}{l}\text { Porcentaje } \\
\text { del total }\end{array}$ & 3.46 & 0.36 & $(100)$ & & & \\
\hline
\end{tabular}

Total

Impugnados No utilizados

Extraviados Total

Porcentaje

del total

$$
1490306
$$$$
92012919000
$$

Fuente: Consejo Central de Elecciones

Tomado de: Ricardo Córdova, "Periodización del proceso de crisis", op. cit., p. 98.

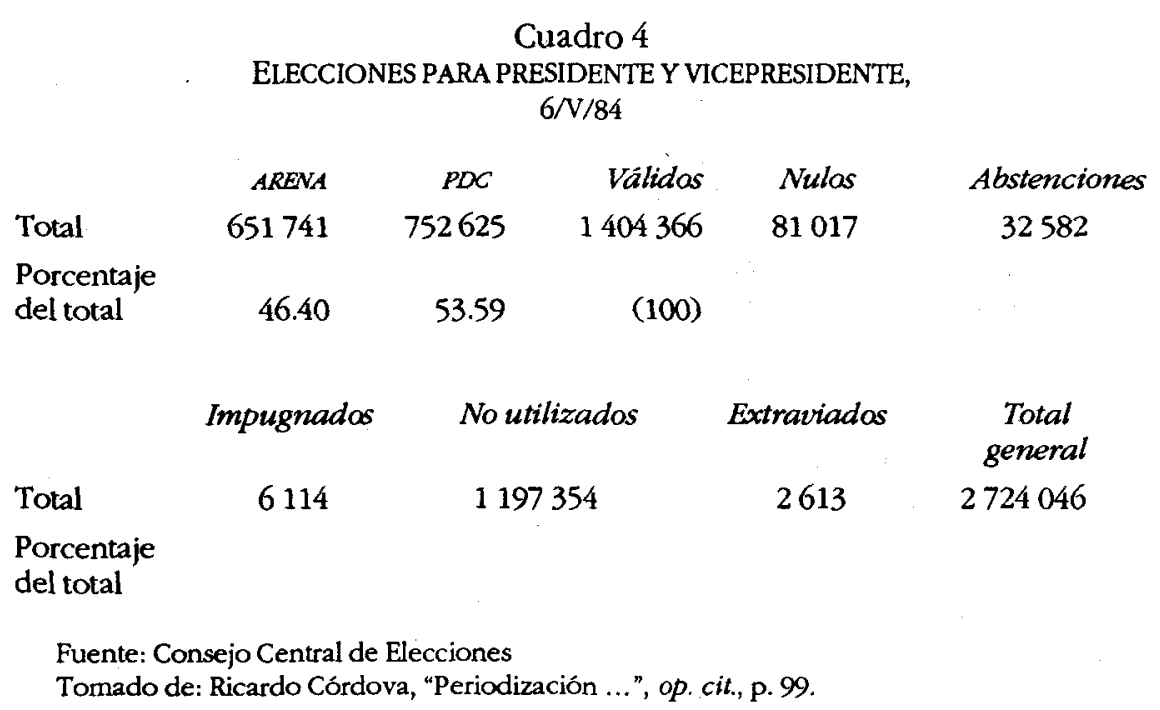




\section{Cuadro 5 \\ RESULTADOS ELECCIONES PARA DIPUTADOS, \\ $31 / \mathrm{II} / 85$}

\begin{tabular}{lccrrrr}
\multicolumn{1}{c}{$P$ PDC } & ARENA & PCN & PAISA & PPS & AD \\
Total & 505338 & 286665 & 80730 & 36101 & 16344 & 35565 \\
$\begin{array}{l}\text { Porcentaje } \\
\text { del total }\end{array} 52.35$ & 29.69 & 8.36 & 3.74 & 1.7 & 3.68
\end{tabular}

$\begin{array}{ccccccc} & \text { POP } & \text { MERECEN } & \text { PAR } & \begin{array}{c}\text { Total } \\ \text { Válidos }\end{array} & \text { Abstenciones } & \text { Nulos } \\ \text { Total } & 836 & 689 & 2963 & 965231 & 57690 & 74007\end{array}$

Porcentaje

del total $\quad 0.8$

0.7

2.9

(100)

Impugnados

Total

Porcentaje

del total

4678
Faltantes

No utilizados

5866

1452528
Total

general

Fuente: Consejo Central de Elecciones tomado de: Ricardo Córdova, "Periodización ...", op. cit., p. 100.

1986 se observa ya un descontento de la población debido a que las promesas de campaña se enfrentan a la realidad: el presidente no tiene una capacidad real para negociar la paz, pues debe consultar cualquier esfuerzo incluso sólo limitado al diálogo con el FDR-FMLN con los dos factores de poder: el alto mando de las fuerzas armadas y Estados Unidos. Igualmente, la crisis económica no se puede resolver, ni de forma súbita o espontánea como había prometido Duarte, ni en sus raíces, por la realidad de la guerra civil. Por el contrario, la situación económica se agrava, entre otros factores, por la desconfianza del sector privado y la destrucción de la infraestructura por el FMLN, siendo imposible lograr la reacti-

(ECA), año XLIII, núms. 473-474, abril de 1988, San Salvador, p. 182. vación, ${ }^{21}$ además de que la estructura económica sufre una profunda mutación hacia una economía de guerra desde principios de los ochenta, transformación donde sobresale la participación de Estados Unidos en ayuda económica y militar, superando ésta los 4000 millones de dólares entre 1980 y $1989^{22}$ y la creciente dependencia de los recursos

${ }^{21}$ De 1981 a 1989 el crecimiento del piB total es de $-6.3 \%$. A nivel per cápita, el PIB por habitante desciende en-17.4\%. CEPAL, Centroamérica. Evolución económica en 1989. Apreciación preliminar, LC/MEX/L.129, México, p. 15.

${ }^{22}$ Entre 1981 y 1985 la ayuda total de Estados Unidos a El Salvador suma 1739293000 dólares, de éstos 523100000 dólares (30\%) fueron destinados a ayuda directa para la guerra; 766723000 dólares $(44.1 \%)$ de ayuda indirecta para la guerra; 266993000 dólares (15.4\%) en ayuda para reformas y desarrollo y 182477000 dólares en ayuda en alimentos (10.5\%), Jim Leach et al., "U.S. aid to 
provenientes de los salvadoreños desplazados y refugiados en el exterior, principalmente Estados Unidos (los "pobredólares"). Se calculan entre 500000 y 900000 los salvadoreños residentes en Estados Unidos, ${ }^{23}$ además de los ubicados en México (120 000), Guatemala (70 000), Nicaragua (17 500), Honduras, Costa Rica, Panamá y Belice $(32000) \cdot{ }^{24} \mathrm{~A}$ la situación anterior, también se leagrega una demografia de la guerra en El Salvador que incide notablemente en el comportamiento político (y electoral) de la población: existen casi 400000 habitantes desplazados de sus lugares de residencia, principalmente de las zonas conflictivas hacia la periferia de la capital y el occidente del país. ${ }^{25}$

La situación del país, como se percibe en 1986 y 1987, es, según la mayoría de la población -medida la opinión en encuestas-o mala o muy mala. Una encues-

\footnotetext{
El Salvador: an evaluation of the past, a proposal for the futuren , Arms Control and Foreign Policy Caucus, Washington, D.C., febrerode 1985. Entre 1985 y 1988 la ayuda suma 1978.5 millones de dólares. Su distribución porcentual es similar a la de los años anteriores, Jim Leach et al., "Bankrolling failure: United States policy in El Salvador and the urgent need for reform", Arms Control and Foreign Policy Caucus, Washington, D.C., noviembre de 1987. En 1989 y 1990 se continúa con la misma tendencia, de proporcionar aproximadamente $\mathbf{4 5 0}$ millones de dólares por año en asistencia. Esta cifra supera anualmente al presupuesto del gobierno de El Salvador y desde 1980-81 representa entre 20 y $30 \%$ del PIB.

${ }^{23}$ Segundo Montes, Saluadoneños refugiados en Estados Unidos, vcA, San Salvador, 1987, p. 34.

${ }^{24}$ Edelberto Torres-Rivas, Informe sobre el estado de la migración en Centroamérica, en cINAs, Cuaderno de Trabajo, núm. 7, agosto de 1986, México, p. 9.

${ }^{25}$ Grupo Ad-Hoc, Ministerio de Planificación y Comisión Nacional de Asistencia a la Población Desplazada "La población desplazada 1980-1987", Presencia, cenrrec, año 1, núm. 1, abril-junio de 1988, San Salvador, p. 129.
}

ta de agosto de 1986 señala que $42 \%$ de los salvadoreños urbanos opina que la situación es "muy mala" y $41.7 \%$ señala que es "mala". Sólo $0.3 \%$ de la población menciona que el país está en condiciones "muy buenas" y para $1.3 \%$ el país vive bajo condiciones "buenas". ${ }^{26} \mathrm{En}$ la identificación de los problemas del país, los salvadoreñosmencionan quelos tres principales son la crisis económica, el desempleo y la guerra. En agosto de 1986, en encuestas cuya muestra se restringe a las áreas urbanas, para $68.6 \%$ de la población el principal problema es la crisis económica; para 40.8\% la guerra y la violencia y para $37 \%$ lo es el desempleo. En julio de 1987, la crisis económica es el principal problema para el $66.7 \%$ de los encuestados; la guerra y la violencia para $45.9 \%$ y el desempleo para $32 \%{ }^{27}$ Un aspecto clave que se observa en las encuestas de opinión es el incremento de las personas que opinan que debe de haber un diálogo con el FMLN para solucionar la guerra. En septiembre de 1986, $29.2 \%$ de los entrevistados mencionan que el diálogo debe ser la solución al conflicto, cifra que asciende a $51.1 \%$ en julio de 1987, mientras que las personas que opinan que debe ser derrotado militarmente el FMLN baja de $5.8 \%$ a $5.4 \%$ en las mismas fechas. ${ }^{28}$

Las anteriores encuestas, levantadas en los momentos inmediatos a la firma de los acuerdos de Esquipulas, dan cuenta del apoyo popular que lograron los mismos en El Salvador. ${ }^{29}$ Sin embargo, la

${ }^{26}$ Ignacio Martín Baró, Así piensan los salvadoreños urbanos (1986-1987), vcs, San Salvador, 1987, p. 53.

${ }^{27} \mathrm{Ibid}$., p. 55 . El levantamiento de las encuestas le pide a los entrevistados que mencionen los dos problemas más importantes del país, por lo que las sumas superan 100 por ciento.

${ }^{23}$ lbid., p. 63.

${ }^{29}$ Los acuerdos de Esquipulas II, firmados el 7 de agosto de 1987, mencionan que se debe avan- 
ausencia de soluciones al problema de la guerra y la economía por parte del gobierno de Napoleón Duarte, aun firmados los acuerdos, permiten el ascenso de ARENA en las elecciones de marzo de 1988 debido a dos hechos: por un lado, un "voto de castigo" al PDCy, por el otro, la búsqueda por la población de opciones nuevas. No obstante lo anterior, un sector del FDR decide en noviembre de 1987 reincorporarse a la vida política del país a fin de "abrir los espacios políticos" necesarios para su reinserción. Así, el MNR y el MPSC, junto con el Partido Social Demócrata (PSD), fundan la Convergencia Democrática (CD). ${ }^{30}$

Las elecciones parlamentarias y municipales celebradas el 20 de marzo de 1988 , debido a que no se logra la incorporación de la insurgencia al proceso legal-institucional, se transforman en el principal evento político del país. Para la insurgencia, las eleccionesla colocan ante un desafío difícil, pues la creación de la

zar en la amnistía; cese al fuego; democratización; cese de la ayuda a fuerzas irregulares o a los movimientos insurreccionales y el no uso del territorio para agredir a otros estados. En El Salvador hubo un cumplimiento formal de los mismos por parte del gobierno. Se forma una Comisión Nacional de Reconciliación el 7 de septiembre, se emite un Decreto de Amnistia el 5 de noviembre y se realiza una reunión de diálogo con representantes del FDRFMLN y el gobierno el 4 y 5 de octubre de 1987. Sin embargo, no se logra un acuerdo entre las partes para el cese al fuego ni se logra una negociación para incorporar al mMLN al proceso político, por lo que los compromisos correspondientes a la "democratización" quedan pendientes, continuando la escalada militar. Ver capítulo v, Ricardo Córdova "El proceso de diálogo-negociación y las perspectivas de paz", en El Salvador: guerra, politica..., op. cit.

${ }^{30} \mathrm{La}$ CD se crea a principios de noviembre de 1987. Ver "Los partidos políticos MNR, MPSC y PSD han dado pie a un proceso de Convergencia Democrática", Estudios Centroamericanos (ECA), núms. 469-470, uCA, El Salvador, nov-dic de 1987, pp. 935-938.
CDhace que, si ésta participa en el evento electoral, estaría legitimando el proceso institucional contrainsurgente (cosa que sucedió con su participación en 1989, comose verá más adelante), lo que podría propiciar una fragmentación en la alianza FDR-FMLN. Y, si no participa, como sucedió debido a que la $\mathrm{CD}$ señaló la ausencia de garantías para sus candidatos, la nueva coalición no plasma el objeto de su creación, que es participar aunque sea sin garantías a fin de crear una nueva alternativa política en el país. El FMLN, al igual que en los anteriores procesos electorales (1982, 1984 y 1985) señaló que las elecciones eran una farsa y que las boicotearía militarmente.

El resultado de las elecciones (ver cuadro 6) le otorga 30 diputados y 178 alcaldías a ARENA, 23 diputados y 79 alcaldías al PDC y siete diputados y alcaldias al PCN. Con posterioridad un diputado del PCN se cambió de partido hacia ARENA, con lo cual ésta logra la mayoría absoluta en la Asamblea. ${ }^{31}$ Estos datos señalan la acelerada polarización política que vive el país, incentivada por el fracaso de los acuerdos de Esquipulas II (que la población atribuye a una incapacidad del PDC), una ausencia de liderazgo ejecutivo, producto, entre otros factores, de la enfermedad del presidente Duarte y una división importante del PDC, que finalmente se escinde en dos. La fracción disidente (que por otra parte es la que controla a los diputados del PDC en la Asamblea) funda el Movimiento Autén-

\footnotetext{
${ }^{31}$ Gabriel Gaspar, El Salvador: el ascenso de la nueva derecha, cinss, San Salvador, 1989. Ver capitulo 3 "Las elecciones de marzo de 1988", pp. 69-95. Ver también el editorial de la revista Estudios Centroamericanos, titulado "Elecciones aleccionadoras" y el artículo de Segundo Montes "Las elecciones del 20 de marzo de 1988", Estudios Centroamericanos, año xull, núms. 473-474, marzo-abril de 1988, San Salvador.
}

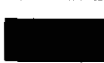




$\begin{array}{ccccccc} & P D C & \text { ARENA } & P C N & \text { PAISA } & A D & \text { POP } \\ \text { Total } & 326716 & 447696 & 78756 & 19609 & 16211 & 1742\end{array}$

Porcentaje

$\begin{array}{llll}\text { del total } & 35.1 & 48.1 & 8.46\end{array}$

Cuadro 6

ELECCIONES PARA DIPUTADOS, 20/III/88

$\begin{array}{lccccc} & \text { PAR } & \text { Liberación } & \text { Impugnados } & \text { Nulos } & \text { Abstenciones } \\ \begin{array}{l}\text { Total } \\ \begin{array}{l}\text { Porcentaje } \\ \text { del total }\end{array}\end{array} & 5059 & 34960 & 11388 & 107355 & .34320 \\ & & & & & \end{array}$

Inutilizados Sobrantes Faltantes $\begin{gathered}\text { Total } \\ \text { válidos }\end{gathered}$

$\begin{array}{lllll}\text { Total } & 65510 & 708284 & 2612 & 930749\end{array}$

Porcentaje

del total

Fuente: Consejo Central de Elecciones tomado de: Ricardo Córdova, "Periodización ...", op. cit., p. 100.

tico Cristiano (MAC). La polarización política también se produce por el agravamiento de los hechos militares. En los altos mandos hay un cuestionamiento importante a la conducción estratégica de la guerra que lleva a cabo Estados Unidos a través del U.S. Military Group, conocida como "guerra de baja intensidad". ${ }^{32}$ Entre marzo y junio de 1988 cambian la mayoría de los mandos militares, y se fortalece la fracción denominada La Tandona, que sostiene abandonar la "guerra de baja intensidad" y pasar a "la guerra total" (estrategia de ge-

\footnotetext{
${ }^{32}$ Esto es analizado en detalle, para el caso centroamericano, en Lilia Bermúdez Guerra de baja intensidad. Reagan contra Centroamérica, Siglo XXI, México, 1987. Para el caso de El Salvador, ver A. J. Bacevich, James Hallums, Richard White, Thomas Young, American military policy and the lessons learned from El Saluador, The John F. Kennedy School of Government, marzo 1988.
}

nocidio, similar a la empleada en Guatemala entre 1980 y 1985). Esta misma posición es sostenida por la dirigencia de ARENA. ${ }^{33}$

En el diseño contrainsurgente, las elecciones forman parte del proyecto de recomposición hegemónica, además del esfuerzo propiamente militar, de la reconstrucción económica y de la búsqueda de legitimidad internacional. En el alto mando del ejército salvadoreño, se cuestiona el plan contrainsurgente debido a que se afirma que se es muy tolerante en lo político con la oposición. A su vez, Estados Unidos sostiene que las concepciones de guerra total entorpecen el éxito para lograr la estabilidad necesaria a fin de aislar al FMLN. Esta contradicción

33 "La crisis del gobierno salvadoreño provocará el cambio de mandos militares", Proceso, núm. 608, 27 de junio de 1988, México, p. 43. 
en la conducción de la guerra existe desde 1980 y se agudiza de 1987 en adelante. En las fuerzas armadas es donde se dan los mayores obstáculos para permitir la participación política de la $\mathrm{CD}$ y, por supuesto, es donde se entorpecen y estancan las propuestas de incorporación del FMLN a la vida política.

Desde la firma de los acuerdos de Esquipulas II, paulatinamente el eje de gravedad del conflicto salvadoreño se desplaza de los acontecimientos propiamente militares a los políticos. La reactivación de la lucha política se da en todos los niveles: en el proceso político institucionalizado se circunscribe a la competencia entre ARENA y el PDC, en la lucha política interna, entre ARENA y el PDC y la posibilidad de participación de la $\mathrm{CD}, \mathrm{y}$ en lo internacional, entre el régimen y el FMLN.

El año de 1988 es de suma importancia, pues para todas las fuerzas políticas la lucha se concentra de cara a las elecciones presidenciales de marzo de $1989 .{ }^{34}$ Para ARENA, es muy importante la búsqueda del triunfo absoluto que le permita controlar tanto la Asamblea como la presidencia. No sufrir un descalabro y que no se dé algún acontecimiento que obstaculice la carrera por la presidencia es crucial para este partido. Para el PDC, escindido, es clave el fallido empeño por no perder la presidencia. Para el resto de los partidos que participan, las pequeñas cuotas de poder -0 no tan pequeñas, como es el caso de la lucha por el tercer puesto, pues significa un cargo en el Consejo Central de Elecciones- son muy relevantes. Al respecto, se menciona a la $\mathrm{CD}$ como la tercera fuerza indiscutible, según todas las en-

${ }^{3}$ Los principales candidatos presidenciales son: ARENA: Alfredo Cristiani; PDC: Fidel Chávez Mena; CD: Guillermo Ungo; PCN: Rafael Morán. cuestas de opinión realizadas durante la campaña electoral. ${ }^{35}$ Para los pequeños partidosubicados entre el centro político y la derecha (PCN, MAC, la coalición denominada Unión Popular -UP-, Acción Democrática $-A D-$, y PAR) la elección también es de suma importancia, pues si no obtienen más de $0.5 \%$ de la votación, la Ley Electoral señala que se debe cancelar su registro. Estos pequeños partidos han ido perdiendo simpatía en la población debido a que sus votantes potenciales concentran su atención en la competencia ARENA-PDC. Finalmente, el gran ausente de la elección presidencial de 1989, el FMLN, también se encuentra ante un momento muy importante y decisorio por la elección. En los cinco procesos electorales anteriores, el FMLN pasa de boicotear explícitamente la elección sin éxito (por ejemplo la elección de 1982), a mencionar que el día del escrutinio es un día más de la guerra (1985 y 1988), y que habrá acciones militares de acuerdo al plan general de guerra. En la elección presidencial de 1989 el FMLN se encuentra ante distintas opciones. La primera de ellas es el boicot militar. El problema de esta opción es que al participar la $\mathrm{CD}$, coalición donde hay fuerzas políticas del FDR, el FMLN se encuentra ante un gran dilema político: no aceptar la representación de la CD

\footnotetext{
${ }^{35}$ Ver 1) IUdop-UCA, "Los salvadoreños ante la elección presidencial de 1989", San Salvador, núm. 18,6 de diciembre de 1988. Encuesta realizada entre el 29 de octubre y el 15 de noviembre de 1988 ; 2) cINAs, "El proceso electoral salvadoreño 1989. Análisis de resultados de un sondeo de opinión sobre las tendencias políticas de la ciudadania", San Salvador, enero-febrero de 1989, encuesta realizada entre el 14 y16 de enero de 1989; 3) Greenberg-Lake The Analysis Group Inc., "El Salvador national election survey", febrero 1989 , encuesta realizada entre el 28 de enero y el 8 de febrero de 1989.
}

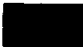


porque no hay participación de sus propias fuerzas políticas. La segunda es buscar su propia participación, reconociendo la institucionalidad existente. Esta opción la buscó afanosamente a partir de su propuesta de modificación del calendario electoral, señalando que el escrutinio debía realizarse hacia el 15 de septiembre.$^{36}$ La tercera opción era no boicotear la elección aunque no tuviera participación propia. El FMLN optó por la primera alternativa.

La campaña electoral se desarrolló en dos fases. Desde su arranque hasta el 23 de enero, y del 23 de enero al 18 de marzo. La fecha de corte está signada por el impacto que tuvo la propuesta de la insurgencia en la vida política de El Salvador. En la primera fase las distintas fuerzas políticas que participan (excepto la $\mathrm{CD}$ ) hacen abstracción de que el problema político central del país es la guerra y que requiere de una solución urgente. ARENA, MAC, PAR, UP y PCN concentran su discurso de campaña en criticar al PDC por su gestión de gobierno, principalmente de la crisis económica, y recurren a acusaciones constantes al PDC y al presidente Duarte, asi como a su ex ministro de planeación, Fidel Chávez Mena. La campaña se concentra en señalar que el país vive la crisis actual por corrupción administrativa, estatización de medios de producción, medidas socializantes -como la reforma agraria-, etcétera. El PDC concentró su discurso en la defensa de las medidas adoptadas por Duarte y en el planteamiento de la necesidad de impulsar numerosas reformas adminis-

\footnotetext{
36 "Propuesta del FMLN para convertir las elecciones en una contribución a la paz", 23 de enero de 1989, en Ricardo Córdova Macias y Raúl Benítez Manaut (comps.) La Paz en Centroamérica. Expediente de documentos fundamentales (1979) 1989), CIH-UNAM, México, 1990, pp. 139-141.
}

trativas y de planificación para resolver los escollos más importantes. En síntesis, el eje de la campaña de todo este conglomerado de partidos es señalar la crisis como producto de una grave situación económica y proponer nuevas alternativas. La CD fue la única fuerza política que centró su atención en el problema de la guerra, y la necesidad de lograr la paz, desde que comienza su campaña. ${ }^{37}$

A partir de la propuesta de la insurgencia de convertir las elecciones en una contribución a la paz, se desata una discusión política de la cual ninguna fuerza se puede evadir. ${ }^{38}$ Así, el eje de gravitación de los discursos de campaña da un giro de $180^{\circ}$ y se transforma en un debate sobre la posibilidad de la incorporación o no del FMLN al proceso político-electoral. ARENA es quien se opone con más énfasis a la participación del FMLN o al cambio de fecha. Ello se debe a que el clima político existente en el país le favorecía grandemente y no iba a desaprovechar la oportunidad de triunfar y ocupar la presidencia. Se realizan encuentros con el FMLN, y finalmente éste decide no participar debido a que no se consideran viables los requisitos que se mencionan como indispensables para su participación, principalmente porquelos partidos deciden no cambiar la fecha del escrutinio. ${ }^{39}$

${ }^{37}$ Ver Plataforma Programática de la Convergencia Democrática, San Salvador, septiembre de 1988.

${ }^{38}$ Ricardo Córdova "El Salvador: el tema de la paz en el debate electoral", ponencia presentada en el XV Congreso de Latin American Studies Association (LASA), Miami, diciembre de 1989.

${ }^{39}$ Ver los siguientes documentos: "Respuestas del FMLN a los partidos políticos" ( 14 de febrero de 1989); "Propuesta del FMLNa los partidos políticos" (20 de febrero de 1989); "Posición del FMLN para que la implementación y realización de nuestra propuesta sobre las elecciones conduzca a una fi- 
Las elecciones del 19 de marzo de 1989 se producen en un país en guerra El proceso estuvo marcado por el paro al transporte decretado por el FMLN entre el 16 y el 20 de marzo. Este boicot afectó notablemente la concurrencia de la población a las urnas por diversos factores. El principal es que los centros de votación en las ciudades grandes se ubicaban a gran distancia de los lugares de residencia de las mayorías. En San Salvador los centros de votación se ubicaron en el centro de la ciudad y el boicot hizo imposible el empleo del transporte público para el traslado de los votantes. Esto favoreció notablemente a ARENA, debido a que previó este fenómeno y recurrió al traslado de sus simpatizantes en transportes alquilados. Por el boicot, los principales perjudicados fueron el PDC y la $\mathrm{CD}$.

El resultado electoral, aunque sin grandes sorpresas, sí sorprendió a un conglomerado importante de analistas, pues se afirmaba que la elección iría a una segunda ronda (ver cuadro 7). ARENA

nalización definitiva de la guerra" (21 de febrero de 1989); "Presidente constitucional de la república y comandante general de las fuerzas armadas, ingeniero José Napoleón Duarte. Mensaje a la nación" (febrero de 1989); "Unión Popular, coalición integrada por los partidos Liberación, Auténtico Institucional Salvadoreño, y Popular Salvadoreño, en relación al documento 'Propuesta del FMLN para convertir las elecciones en una contribución a la paz", (febrerode 1989); "Declaración de los partidos políticos en Oaxtepec, México, sobre la reunión que tuvieron con el FMLN" (21 de febrero de 1989); "'Propuesta de paz en democracia y libertad' del ingeniero Napoleón Duarte al pueblo salvadoreño" (26 de febrero de 1989); "Comunicado del FMLN en respuesta a contrapropuesta del presidente Duarte" (27 de febrero de 1989); "Propuesta de paz de la Convergencia Democrática" (4 de marzode 1989). Ver en Ricardo Córdova Macias y Raúl Benítez Manaut (comps.), La paz en Centroamérica ..., op. cit., pp. 141-164. logró $53.82 \%$ de los votos y el PDC $36.03 \%$. El PDC esperaba que ARENA no alcanzara la mayoría absoluta para, en la segunda ronda, realizar alianzas con otros partidos y así poder competir con ARENA. De hecho, el factor decisivo fue el paro al transporte decretado por el FMLN. Se menciona que el FMLN "colaboró" con ARENA a fin de acelerar la polarización del país. Esto se basa en la hipótesis de que ARENA es representante directa de la oligarquía, y además no tiene contradicciones importantes con los mandos militares, por lo que podía impulsar un proceso negociador sin el veto militar -como sucedió en las rondas de conversaciones entre Duarte y el FMLN. Esta hipótesis fue parcialmente demostrada con las conversaciones impulsadas entre el gobierno de Cristiani y el FMLN en septiembre y octubre. ${ }^{40}$ No obstante, éste no tomó en cuenta que la concepción de ARENA, el alto mando de las fuerzas armadas y Estados Unidos, era que el FMLN buscó, con su propuesta de incorporación al proceso político de enero de 1989, y con su asistencia a las pláticas en septiembre y octubre, su reinserción a la vida política por su debilidad militar. Por ello las delegaciones gubernamentales eran de muy bajo nivel, y se afirmaba que también por esa razón la delegación insurgente lo era con su comandancia general.

40 Ver: "Propuesta del FMLN para lograr la democratización, el cese de hostilidades y la paz justa y duradera en El Salvador" (11 de septiembre de 1989); "Acuerdo de México. Gobierno de El Salvador-FMLN" (15 de septiembre de 1989); "Proposición del gobierno de la república para lograr la paz, consolidar la democracia en el país $y$ reunificar a la sociedad salvadoreña" (16 de $\propto$ tubre de 1989), en Ricardo Córdova Macías y Raúl Benítez Manaut (comps.), La Paz en Centroamérica..., op. cit., pp. 165-175. 
Total

4609

4363

3207

4.07

0.99

3.80

Porcentaje

del total

0.49

0.46

0.34

Nulos

Abstenciones

Total

de votos

Total

51182

7409

1003153

Porcentaje

del total

Fuente: Ricardo Córdova, "El Saivador: análisis de las elecciones presidenciales de 1989", Presencia, año ll, núm. 5, 1989, San Salvador, p. 88.

Otra sorpresa de la elección es la baja votación para la CD y su desplazamiento del tercer puesto por el PCN. Esto le arrebata a la coalición progresista la posibilidad de participar en el Consejo Central de Elecciones. La CD obtiene 3.8\% de los votos y el PCN $4.07 \%$. Al respecto, se afirma que el PCN tiene arraigo en algunas zonas rurales del país, a demás de que la CD pudo ser objeto de un pequeño fraude ya que en numerosas localidades no tenía vigilantes de casilla. Además, la baja votación de la $C D$ también se debió al veto del FMLN, a la propaganda asimilando al FMLN con sus candidatos y dirigentes y al paro al transporte.

Analizando cuantitativamente los resultados electorales de 1989, y comparando las tendencias observadas en el conjunto de la década, se observa un descenso importante de votantes comparando las elecciones de 1982 y 1984 con las de 1985,1988 , y 1989 (ver cuadro 8). De un total de 1362339 de votantes en 1982, que subió a 1404366 en la segunda ronda para las elecciones presidenciales de mayo de 1984, hay una caída creciente que llega a 939078 votos válidos en la elección presidencial de 1989. Esto puede ser resultado del desencanto de la población por el proceso electoral, debido a que las promesas de campaña no se cumplen, sean de resolución de la crisis económica o la solución definitiva de la guerra. En las elecciones de 1989, la concurrencia a lasurnas superóligeramente el millón de personas. Cálculos sobre la población mayor de 18 años en El Salvador, mencionan que la población potencial votante es de 2.3 a 
Cuadro 8

ELECCIONES EN LA DÉCADA DE LOS OCHENTA. TOTAL DE VOTOS VÁLIDOS

Añoelección
1982
$1984-1$
$1984-2$
1985
1988
1989

Total de votos válidos

1362339

1266276

1404366

982766

937946

939078

Fuente: Ricardo Córdova, "El Salvador: análisis de las elecciones...", op. cit., p. 96.

2.5 millones. Los ciudadanos empadronados alcanzan la cifra, para 1989 , de 1800000 y no se le entregó el carnet electoral a aproximadamente 400000 ciudadanos. Por ello, la abstención es menor de $50 \%$. Esta cifra no es extraordinaria comparada con la de otros países. México y Estados Unidos tienen una participación electoral menor que su ciudadanía, factor al que se añade el hecho de que en estos dos países las votaciones son por lugar de residencia (por lo que la urna está muy cerca del hogar del ciudadano). En cambio, en El Salvador, los centros de votación, repartidos por orden alfabético, se encontraban lejos de la residencia del ciudadano, por lo que su asistencia es un verdadero acto de fe, sobre todo si se toma en cuenta la adversidad provocada por el paro al transporte y los hechos bélicos registrados el día de la elección.

Otro elemento a tomar en cuenta en la década de los ochenta, circunscrito al fenómeno electoral, son lassimpatías partidarias de los votantes. Se puede afirmar sin temor a la equivocación, que la ciudadanía que participa activamente del proceso, es simpatizante incondicional ("voto duro") del partido político por el cual vota. Existe un espectro de 900000 personas que bajo cualquier circunstancia opta por partidos de derecha o extre- ma derecha (los 939078 votos válidos en la elección de 1989, menos los 35642 votos para la $\mathrm{CD}$ ) (cuadro 7). ARENA tiene un "voto duro" de casi 300000 ciudadanos (cuadro 9). El PDC tiene un "voto duro" de 330000 personas (cuadro 10). Mientras que baja dramáticamente el voto $\mathrm{pa}-$ ra el resto de los partidos de la derecha salvadoreña, para sumarse principalmente a ARENA.

En estas circunstancias, es muy dificil afirmar cuál sería el "voto duro" de una coalición como la CD, pues en 1989 es la primera vez que participa del proceso, en condiciones económicas y políticas muy adversas. Igualmente difícil es el cálculo de las simpatías que tendría el FMLN si llega a participar de un proceso electoral.

Con las elecciones del 19 de marzo de 1989, El Salvador regresa al tradicional esquema oligárquico de dominación política. ${ }^{11}$ El Estado es controlado por los representantes directos de la oligarquía y

${ }^{4}$ Un análisis de conjunto del proceso electoral puede verse en Ricardo Córdova, "El Salvador: análisis de las elecciones presidenciales de marzo de $1989^{\prime \prime}$, Presencia, año It, núm. 5, abril-junio de 1989, San Salvador. Y Gabriel Gaspar, El Salvador: el ascenso ..., op. cit., capítulo 4 "Las elecciones presidenciales en El Salvador, trayectoria, balance y perspectivas". 
Cuadro 9

VOTOS PARA ARENA EN LOS OCHENTA

$\begin{array}{ccc}\text { Añoelecciōn } & \text { Votos välidos } & \text { Porcentaje } \\ 1982 & 402304 & 29.53 \\ 1984-1 & 376917 & 29.76 \\ 1985 & 286665 & 29.69 \\ 1988 & 450100 & 47.99 \\ 1989 & 505370 & 53.82\end{array}$

Fuente: Ricardo Córdova, "El Salvador: análisis de las elecciones..." op. cit., p. 96

VOTOS PARA EL PDC EN LOS OCHENTA

$\begin{array}{ccc}\text { Añoelección } & \text { Votos válidos } & \text { Porcentaje } \\ 1982 & 546218 & 40.09 \\ 1984-1 & 549727 & 43.41 \\ 1985 & 505338 & 52.35 \\ 1988 & 330324 & 35.22 \\ 1989 & 338369 & 36.03\end{array}$

Fuente: Ricardo Córdova, "Periodización del proceso de crisis...", op. cit, p. 98.

éstos están apoyados totalmente por el alto mando. ARENA ejerce el poder de manera total e incluso numerosos observadores mencionan que lo hace de forma "prepotente". O sea, sin tomar en cuenta al resto de las fuerzas políticas del país. Por ello, desde que se da la transmisión de la presidencia a Alfredo Cristiani el 1 de junio de 1989 , se inicia sin contemplación la ejecución de sus dos principales proyectos: la liberalización de la economía y la represión indiscriminada, con la consecuente crisis social y política. Incluso las reformas planificadas por Estados Unidos y realizadas por el PDC se cuestionan y se plantea su reversión. Además, uno de los mitos que despeja el triunfo de ARENA es que este partido estaba vetado por Estados Unidos, debido a la vinculación de algunos de sus diri- gentes con los "escuadrones de la muerte". Para Estados Unidos el gobierno de ARENA es legítimo, por ser producto de un proceso electoral, y por ello debe ser apoyado. ${ }^{42}$ Además, ARENA no se opone en absoluto a los planes de contrainsur-

${ }^{42}$ Para Estados Unidos, la "democracia" en El Salvador no es importante. Lo relevante es que el proceso político, sea cual fuere la fuerza política que lo encabece, logre la estabilidad y logre evitar el triunfo $y$, de ser posible, la participación del FMLN. De esta manera, Estados Unidos promueve la democratización a través de las elecciones para este fin. Por ello, las elecciones son "elecciones de demostración" y se promueven para evitar que aparezcan obstáculos para la dotación de asistencia económica y militar. Este argumento es desarrollado en Edward Herman y Frank Brodhead, Demostration elections. U.S. staged elections in the Dominican Republic, Vietnam and El Salvador, Southend Press, Boston, 1984. 
gencia. Por el contrario, señala que ésta debellevarse a cabo sin "obstáculos políticos". Para este objetivo, incluso modifica la legislación para poder actuar sin obstáculos hacia los sectores "simpatizantes" del FMLN en las ciudades. ${ }^{43}$

Entre los principales objetivos de ARENA están el hegemonizar al conjunto de fuerzas políticas, económicas y militares que integran el actual bloque en el poder. En los planes de ARENA, no se contempla la incorporación del FMLN al proceso político. Incluso la participación de la CD está condicionada de alguna manera a la disolución de la alianza FDR-FMLN. De cualquier manera, el sistema político, al ser excluyente del conjunto de las fuerzas políticas, hace que la legitimidad lograda por ARENA sea muy precaria y pueda tambalearse rápidamente por circunstancias que están fuera de su control o por excesos en el ejercicio del poder. ${ }^{44}$

\footnotetext{
${ }^{43}$ CARECEN, Legalizing repression: ARENA's reform of the salvadoran penal and criminal procedure codes, Summary of Report by U.S. Attorney Delegation, Washington, diciembre 1989.

${ }^{44}$ Después de la elección y principalmente desde que Cristiani asume la presidencia hay un tensionamientonotable de los acontecimientos de la vida política en el país. Se estrechan los márgenes de acción de las organizaciones gremiales, estudiantiles, de defensa de los derechos humanos, $y$, además, los partidos políticos ven con suma preocupación la acelerada polarización. Esto incluso afecta al PDC. Ver "El Salvador. Post-election tension builds", Central America Bulletin, CARIN, vol.8, núm. 6, mayo,1989, Berkeley; "El Salvador. ARENA takes the helm", Central America Bulletin, vol. 8, núm. 11, octubre, 1989. Ver también el número monográfico de la revista Estudios Centroamericanos, dedicado a los cien primeros dias de gobierno de ARENA, en especial los editorales "Los cien primeros días de ARENA"; Francisco Ibisate, "A los cien dias de gobierno, thacia donde vamos?"; Antonio Cañas, "La guerra en los cien primeros días de Cristiani"; Ignacio Ellacuria, "El diálogo en los cien primeros días de Cristiani"; Claudia Solis, "El movimiento popular a los cien dias del gobierno de ARENA", Estudios Centroamericanos, UCA, año
}

La pregunta obligada, observando el escenario político salvadoreño, es la siguiente ¿cómo, en un país que vive una guerra civil donde uno de sus actores principales es una organización de izquierda armada, y donde participa una coalición de izquierda democrática en las elecciones, gana la derecha de forma abrumadora? De esta pregunta se desprende una afirmación que puede ser muy polémica. En el consenso buscado por el conjunto de fuerzas políticas que participaron en las elecciones, no tiene representación un sector muy importante del electorado potencial. Este sector puede ser simpatizante del FMLN, pero también puede ser un conglomerado de ciudadanos muy disperso, atomizado y despolitizado, abrumado por la guerra y por la crisis económica.

ARENA representa una nueva derecha que ha lanzado una ofensiva política de forma exitosa. Seguramente esta ofensiva política va a ser acompañada de iniciativas militares y diplomáticas que pretenden aislar al FMLN. En lo militar es donde se presentan los principales escollos. En un momento (septiembre-octubre de 1989) se intentó trasladar la guerra a las ciudades a través de una represión indiscriminada contra sectores populares que ARENA acusa de ser simpatizantes de la insurgencia. La respuesta de la insurgencia fue la cancelación de los diálogos iniciados en San José y México y el despliegue de una ofensiva militar, iniciada el 11 de noviembre de 1989, que impactó al conjunto de la sociedad salvadoreña y a la comunidad internacional. Esta ofensiva insurgente revaloró al FMLN y su imagen, principalmente la percepción equivocada de que perdia crecientementefuerza militar. Por

XIsv, núm 490-491, agosto-septiembre de 1989, San Salvador. 


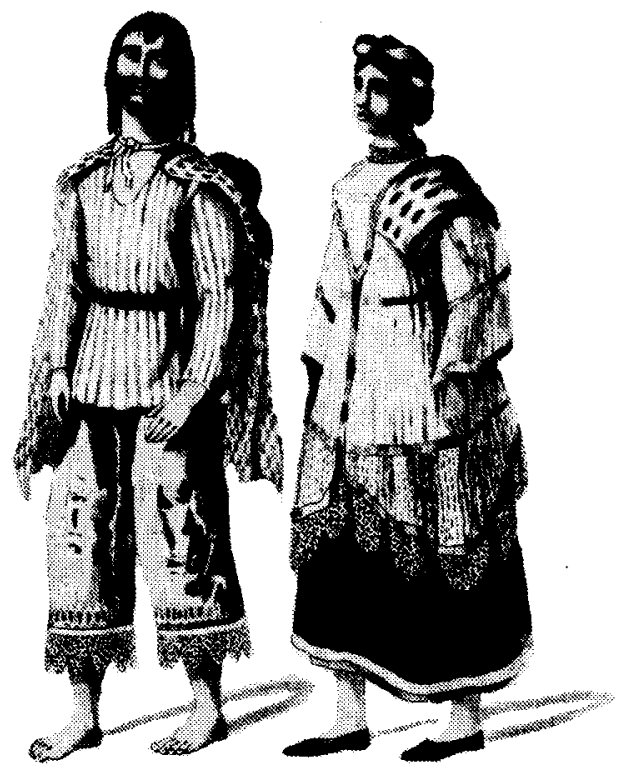

ello, los nuevos esfuerzos de diálogo (y negociación) parten dela premisa deuna dualidad de poderes en lo militar, donde ninguno de los dos ejércitos ha sido debilitado por su contrario. En este diálogo-y posible negociación-, lo que está en juego es la incorporación del FMLN a la vida política del país, lo que modificaría por completo las reglas políticas que rigieron durante todos los procesos electorales en la década de 1980.

En los años noventa, si partimos de la base de que bajo cualquier circunstancia, desde las posibilidades más polares, ubicadas en un extremo en el triunfo militar del FMLN y, en el otro, una intervención militar de Estados Unidos para impedirlo, se realizarían procesos electorales. Si triunfa el FMLN, éste no puede evadir medir su verdadera fuerza en un proceso electoral. Si ARENA se consolida en el gobierno, tampoco puede impedir la realización de los comicios. Si hay una negociación política, también la forma en cómo se repartiría el poder político se concentraria en un plebiscito, y si, en un caso extremo, Estados Unidos decide invadir El Salvador, también buscaría la legitimidad apoyando a fuerzas políticas locales y por supuesto tendría que convocar a elecciones. ${ }^{45}$

${ }^{45}$ Desde la ofensiva del FMLN de noviembre de 1989 , se vuelve a discutir como estratégico para el futuro de la política norteamericana en Centroamérica, el caso salvadoreño. Las distintas opciones vuelven a replantearse, desde el apoyo al gobierno, dado que es "democrático", hasta planteamientos en el Senado y la Cámara de Representantes para el corte de la ayuda. Ver Tommie Sue Montgomery "Fighting Guerrillas: the United States and low intensity conflict in El Salvador", Paper Prepared for Delivery at the XVII International Congress of the Latin American Studies Association (IASA), Miami, diciembre 1989; Department of State, "Testimony of Bernard W. Aronson, Assistant Secretary of State", Bureau of Interamerican Affairs, Subcommittee of Western Hemisphere Affairs, Committee on Foreign Affairs, House of Representatives, 24 de enero de 1990 . 